\title{
METODOLOGIAS ATIVAS COMO MEDIAÇÃO PEDAGÓGICA NO ENSINO SUPERIOR
}

\author{
Marcelo da Silva Reis ${ }^{1}$ \\ Neide Pena ${ }^{2}$
}

\begin{abstract}
RESUMO: O debate em torno das metodologias ativas na educação superior é um tema que tem conquistado espaço no meio acadêmico nos últimos anos. Um dos fatores relevantes nesse debate é a questão do ensino e da aprendizagem no nível superior, tema este até bem recentemente desconsiderado nas discussões acadêmicas e no campo da pesquisa. Nesse debate, o uso de metodologias ativas no ensino superior equivale a um recurso pedagógico promissor no que se refere à melhoria da aprendizagem e, consequentemente, da educação. $O$ artigo se origina da pesquisa de mestrado em que foi investigada uma experiência com metodologias ativas em um curso de Administração, por meio de uma pesquisa de campo, do tipo Survey, com os alunos participantes da experiência, a fim de servir de fundamento teórico-científico a novas práticas pedagógicas de professores que desejem estimular a participação dos alunos e desenvolver a autonomia no processo de autoaprendizado. Constatou-se que as metodologias ativas representam ferramentas fundamentais na mediação pedagógica, em que aluno e professor tornam-se protagonistas e sujeitos ativos, que se interagem e trocam constantemente informações, fazendo da situação da aula uma oportunidade de desenvolver aprendizagens significativas.
\end{abstract}

Palavras-chave: Aprendizagem. Metodologias Ativas. Ensino Superior.

\footnotetext{
${ }^{1}$ Bacharel em Administração. Mestre em Educação pela Universidade do Vale do Sapucaí (Univás). Docente da Universidade Presidente Antônio Carlos, professor se cursos presenciais e EaD da Universidade Vale do Rio Verde de Três Corações-MG. E-mail: prof.marcelo.reis@unincor.edu.br

2 Pedagoga. Doutora em Educação pela Pontifícia Universidade Católica de São Paulo (PUC/SP). Coordenadora e docente permanente do Mestrado em Educação da Universidade do Vale do Sapucaí (Univás).E-mail: neideunivas@gmail.com
} 


\section{ACTIVE METHODOLOGIES AS PEDAGOGICAL MEDIATION IN HIGHER EDUCATION}

ABSTRACT: The debate on active methodologies in higher education is a topic that has gained ground in academic circles in recent years. One of the relevant factors in this debate is the issue of teaching and learning at a higher level, a topic that until recently has been overlooked in academic discussions and in the research area. Having in mind the considerable increase in the number of students entering higher education and considering the new demands of the working world nowadays, it can be observed in recent years an intense debate regarding the quality improvement of education. In this debate, the use of active methodologies in higher education is equivalent to a promising pedagogical resource in relation to improving learning and, consequently, education. The article originates from the research of master's dissertation in which an experience with active methodologies was investigated in a course of Administration, through a field research, of the type Survey, with the students participating in the experience, in order to serve as a foundation theoretical-scientific to new pedagogical practices of teachers who wish to stimulate student participation and develop autonomy in the self-learning process. It was observed that active methodologies represent fundamental tools in pedagogical mediation, where student and teacher become protagonists and leading actors, who interact and constantly exchange information, making the class environment an opportunity to develop meaningful learning.

Keywords: Learning. Active Methodologies. Higher Education.

\section{METOdOLOGÍAS ACTIVAS COMO MEDIACIÓN PEDAGÓGICA EN LA EDUCACIÓN SUPERIOR}

RESUMEN: El debate sobre metodologías activas en la educación superior es un tema que ha ganado terreno en los círculos académicos en los últimos años. Uno de los factores relevantes en este debate es el tema de la enseñanza y el aprendizaje a un nivel superior, un tema que hasta hace poco se había pasado por alto en las discusiones académicas y en el área de investigación. Teniendo en cuenta el considerable aumento en el número de estudiantes que ingresan a la educación superior y considerando las nuevas demandas del mundo laboral en la actualidad, se puede observar en los últimos años un intenso debate sobre la mejora de la calidad de la educación. El artículo se origina en la investigación de la disertación de maestría en la que se investigó una experiencia con metodologías activas en un curso de Administración, a través de una investigación de campo, del tipo Encuesta, con los estudiantes que participan en la experiencia, para servir 
como base Teórico-científico a nuevas prácticas pedagógicas de docentes que desean estimular la participación de los estudiantes y desarrollar la autonomía en el proceso de autoaprendizaje. Se observó que las metodologías activas representan herramientas fundamentales en la mediación pedagógica, donde el alumno y el maestro se convierten en protagonistas y actores principales, que interactúan e intercambian información constantemente, lo que hace que el entorno de clase sea una oportunidad para desarrollar un aprendizaje significativo.

Palabras clave: Aprendizaje. Metodologías activas. Educación superior.

\section{Introdução}

O uso de metodologias ativas tem sido apresentado como estratégia para atender às novas necessidades e demandas do ensino superior e melhorar a qualidade das práticas educativas, no contexto de uma conjuntura que envolve elementos de diversas ordens (MASETTO, 2010), dentre elas a crítica à metodologia tradicional ainda predominante do ensino (CUNHA, 2009). A ideia apresentada pela literatura sobre o tema é que as metodologias ativas tornam a aprendizagem mais ativa, porque estimula a participação do aluno no seu próprio processo de aprendizagem e formação (CUNHA, 2010; BERBEL, 2011; MASETTO, 2012), entretanto, o que está em questão é uma superação do paradigma tradicional do conceito de conhecimento e de aprendizagem (CUNHA, 2006). Para romper com paradigma tradicional faz-se necessário "romper com as regularidades propostas" para que ocorra uma "reconfiguração do conhecimento, não somente com a inserção de novidades e tecnologias, mas também, relacionando-se à forma de como se entende o conhecimento" (CUNHA, 2006, p. 22).

O que se percebe é que, no caso do ensino superior, as metodologias ativas têm sido utilizadas como estratégia para envolver o aluno no processo de aprendizagem, 
estimulando a autorregulação e a responsabilização do aprendiz, o que traz a ideia de autonomia e tomadas de decisões (MASETTO, 2010). Por se tratar de alunos adultos, os quais já possuem certas experiências, inclusive práticas profissionais e chegam à instituição superior com expectativas de obter a formação e a qualificação para uma profissão, o uso de metodologias ativas pode representar um fator que transcende à situação de uma sala de aula. Isso porque, para muitos desses estudantes, não se trata apenas de obter notas em provas ou exames, mas também de proporcionar uma formação capaz de atender às demandas de formação exigidas pelo mundo do trabalho.

No caso do Brasil, as metodologias ativas mais utilizadas no ensino superior têm sido a sala de aula invertida e a peer instruction, mas de certa forma, elas são adaptadas pelos professores à realidade dos alunos e aos objetivos pretendidos. O professor Eric Mazur, criador da metodologia "peer instruction", tratada como uma "Revolução da Aprendizagem Ativa" (MAZUR, 2015), foi um dos primeiros a utilizar o modelo de sala de aula invertida, mas defende também a modernização dos formatos na educação, a reformulação dos modelos pedagógicos e nas atividades avaliativas.

Originado de uma pesquisa realizada para a dissertação de Mestrado em Educação, este artigo se insere no contexto, ora mencionado, e apresenta análise de uma experiência realizada com metodologias ativas, em sala de aula do Curso de Administração, por mais de três anos, em uma universidade privada, localizada no Sul de Minas Gerais. A discussão se dá em torno dos resultados da utilização de metodologias ativas como recurso de mediação pedagógica em uma sala de aula do ensino superior visando melhorar o interesse dos alunos e a eficácia das práticas educativas. As informações foram obtidas por meio de uma revisão de literatura sistematizada sobre metodologias ativas e um estudo de campo, do tipo Survey, em 
que se investigou a percepção de alunos do último período do curso de Administração, que vivenciaram a uma prática com metodologias ativas ao longo de um semestre.Considerando esses pressupostos sobre a importância da temática acerca das metodologias ativas e o papel que a sua utilização vem assumindo nos processos de ensino, principalmente no contexto da Educação Superior, este artigo tem como foco discutir tais fatores à luz da literatura selecionada e da percepção dos participantes da pesquisa.

\section{Referencial Teórico}

Ao se falar em metodologias ativas o que está em jogo é o redesenho dos espaços de aprendizagem no nível superior, bem como uma reelaboração e adequação de projetos pedagógicos de cursos, com o apoio das tecnologias. Com base em Moran (2007), cabe frisar que esse redesenho não se trata apenas de uma reengenharia estrutural, mas também de uma superação de paradigmas por parte dos profissionais da educação, diante um cenário de mudanças que vêm ocorrendo ao longo das últimas três décadas, pelo menos, o que tem levado a temática ensino-aprendizagem a ocupar amplo espaço no campo da pesquisa em educação.

\section{A docência no ensino superior}

Portador de uma larga experiência em docência no ensino superior, Masetto (2003) tem enfatizado em suas obras que o principal papel do professor na atualidade passou a ser o de mediar os processos que ocorrem em sala de aula para que ocorra uma aprendizagem mais autônoma e eficaz. Com base nisso, o professor deixa de concentrar as suas ações mais no ensinar para focar, também, ações estratégicas que possam estimular o interesse e a participação dos estudantes nas aulas, visando a tornar a aprendizagem mais significativa para 
os estudantes.

O conceito de aprendizagem significativa tem amparo em Ausubel (1973), o qual tem como principal fundamento teórico o envolvimento ativo do sujeito em seu processo de aprendizagem. De acordo com o autor, a aprendizagem significativa consiste em um processo no qual o aluno se relaciona com seu aprendizado não de maneira arbitrária, mas, sim, de forma interativa e significativa, pois, o novo conhecimento que lhe é apresentado provoca uma mudança na estrutura cognitiva, que forma em ambiente propício a um conjunto de novas relações com seus conhecimentos prévios. No entanto, conforme Masetto (2010), embora os alunos tenham seus interesses, quando a aprendizagem se limita às experiências espontâneas dos alunos, os resultados podem ser dispersos e não sistemáticos. Cabe, portanto, ao professor realizar a orientação e a intermediação desse processo para que os conhecimentos sejam sistematizados. Dessa forma, o desenvolvimento cognitivo e as habilidades adquiridas vão se transformando em competências necessárias a serem aplicadas nas diversas situações da vida, auxiliando a tomada de decisões pessoais e no ambiente profissional (MASETTO, 2012).

Masetto (2012) deixa evidente que o protagonista do ensino continua sendo o professor, no papel de liderança do trabalho pedagógico, mesmo utilizando metodologias ativas. Ele ainda ressalta que ensinar exige ações do professor, que atua como agente do ensino, pois, cada vez mais, o professor é a peça-chave no processo educativo. Ou seja, nessa relação de ensino e aprendizagem, as orientações do docente e as expectativas dos alunos devem dialogar com as experiências, tanto do professor como dos alunos, numa relação interativa.

Atualmente, uma grande parte dos professores do ensino superior está preocupada em transmitir suas experiências aos estudantes em formação e, para isso, utilizam praticamente somente aulas teóricas, expositivas e práticas, mas se esquecem de provocar o referido diálogo com os alunos (MASETTO, 2010; 2012). No entendimento do autor, a complexidade desse momento se dá quando o professor se torna o centro das atenções, pois 
ao tentar transferir para o aluno todos os seus conhecimentos habilidades e competências, que são desenvolvidas no mercado de trabalho, ele acaba se esquecendo que a figura mais importante deste processo é o aluno.

Diante desse cenário, as mudanças no ensino, no nível da educação superior, exigem um tempo, mas, por outro lado, não se trata mais de uma opção do professor. Na realidade, com a popularização de tecnologias, cada vez mais avançadas, e com as mudanças no mundo do trabalho, essa relação pedagógica tradicional, principalmente no ensino superior, já está superada, ou pelo menos deveria estar. O conceito de "tradicional", aqui adotado, vem do próprio Masetto (2012, p. 14) como uma relação em que "os conhecimentos e experiências profissionais são transmitidos de um professor, que sabe e conhece, para um aluno, que não sabe e não conhece, seguida por uma avaliação que indica se o aluno está apto ou não para exercer determinada profissão".

Nessa mesma direção, Cunha (2010, p. 526) procura justificar essa prática tradicional da docência no ensino superior, argumentando que, diferentemente dos outros graus de ensino, o professor do ensino superior "se constituiu, historicamente, tendo como base a profissão paralela que exerce ou exercia no mundo do trabalho" e, por isso, por muito tempo, "a ideia de que, quem sabe fazer sabe ensinar deu sustentação à lógica do recrutamento dos docentes". Porém, a situação atualmente é outra, como frisa a autora: observa-se que o ensino superior, além de cumprir seus objetivos, tem a função de formar profissionais e cidadão para uma sociedade em constante evolução. Portanto, trata-se de uma educação que deve articular esse processo dentro da sala de aula, na forma de pesquisas, discussões e demais processos criativos, visando formar profissionais que sejam capazes, inclusive, de continuar aprendendo.

Pelo exposto, pode-se observar que existe um ideal a serem perseguido entre o desenvolvimento profissional do aluno, as características do professor universitário e sua formação. Segundo Cunha (2010), a relação entre esses pilares é que darão sustentação aos processos que tornarão as aulas mais significativas, com abordagens relacionadas à pesquisa 
e ao desenvolvimento de novos modelos e práticas pedagógicas que atendam às necessidades do aluno. Isso vale tanto para aqueles que já são profissionais, inseridos no mercado de trabalho e buscam o ensino superior para desenvolver as suas competências e adquirir qualificação, como para aqueles que estão iniciando o seu processo de formação profissional na expectativa de conquistar seu espaço no mercado.

Cabe lembrar que, no âmago das questões em torno do ensino e da aprendizagem, está em discussão a atuação docente e a sua formação para o exercício desta função. Nessa esteira, sobressaem-se fatores que estão ligados à forma em que se organiza a relação entre ensino e aprendizagem e aos modelos metodológicos utilizados em sala de aula. Como analisado por Cunha $(2009,2016)$, todos os professores já foram alunos de outros professores e viveram as mediações de valores e práticas pedagógicas. Também, absorveram visões de mundo, concepções epistemológicas, posições políticas e experiências didáticas e, uma vez adentrando-se à docência, passam a repetir o que aprendeu quando aluno, pois através das suas experiências, enquanto aluno, foram se formando e organizando, de forma consciente ou não, seus esquemas cognitivos, que acabam dando suporte para a sua futura docência.

Ao observar na literatura visitada que esse aluno do século XXI é mais ativo e envolvido com as tecnologias e, por isso, dotado de experiências e habilidades, é possível problematizar a relação entre professor e aluno em dias atuais, propondo formas mais interativas em salas de aula. De tal conclusão decorre considerar recorrente a necessidade de repensar a atuação e a formação docente no ensino superior. Somente desta forma será possível, gradativamente, quebrar esse ciclo tradicional na educação e superar o paradigma de que o professor é aquele que sabe e ensina ao aluno que não sabe. De acordo com Pimenta e Anastasiou (2010), especificamente no ensino superior, a preocupação com a metodologia de ensino é muito recente, porém, a abordagem tradicional, baseada unicamente na transmissão de conteúdos pelo professor e na passividade do aluno como ouvinte em sala de aula, precisa dar lugar a práticas de ensino inovadoras.

Existe, atualmente, certo consenso em torno da importância do uso de metodologias 
ativas no ensino, principalmente no nível superior, que vem ganhando espaço no cenário educacional, sendo tratadas como metodologia inovadora e, como tal, aproximam-se cada vez mais dos espaços formais de ensino, por trazerem contribuições positivas nos processos de ensino e de aprendizagem. Diante da finalidade da educação superior de desenvolver competências profissionais, conforme Lei de Diretrizes e Bases da Educação Nacional (LDB), no 9394, de 1996 e Diretrizes Curriculares Nacionais, as metodologias ativas têm sido consideradas ideais no aspecto metodológico, como uma forma de colocar esse ambiente em consonância com a evolução e transformação do ambiente externo aos muros da instituição de ensino.

\section{Revisando os conceitos "Metodologia" e "Metodologias ativas"}

Etimologicamente, o termo "Metodologia" é uma palavra derivada de "método", do Latim "methodus" que significa "META" (objetivo, finalidade) e "HODOS" (caminho, intermediação). Por sua vez, "LOGIA" quer dizer conhecimento, estudo. Assim, metodologia significa "o estudo dos métodos, dos caminhos a percorrer, tendo em vista o alcance de uma meta, objetivo ou finalidade" (MANFREDI, 1996, p. 1). A referida autora considera essa formulação um tanto simplista, pois reduziria a definição de metodologia do ensino ao "estudo das diferentes trajetórias formuladas pelos educadores para orientar/direcionar o processo de ensino-aprendizagem em função de certos objetivos ou fins educativoformativos".

Essa conceituação é genérica e abstrata de acordo com a citada autora, pois esclarece tudo, mas não diz nada. Nela, cabe a prática de qualquer educador, seja ele conservador, fascista, humanista, progressista, podendo ser, portanto, uma definição que serviria para todos, como se todas as concepções e práticas metodológicas fossem semelhantes e pouco importasse diferenciá-las (MANFREDI, 1996). A própria autora reconhece que durante muito tempo repetiu e utilizou tal conceituação de metodologia e, somente com o decorrer do tempo, ela foi se dando conta de que o conceito de metodologia do ensino, tal como qualquer 
outro conhecimento, é fruto do contexto e do momento histórico em que é produzido.

Essa argumentação apresentada por Manfredi $(1996$, p. 1) revela "um conceito geral, universalmente válido e a histórico de metodologia", que ainda hoje predomina como conceito de "metodologia de ensino". Ela ressalta que "as diferentes concepções e práticas educativas que, historicamente, deram origem à literatura Ihes deram suporte", precisam ser revisadas para se adequar a um novo contexto. Ao buscar na própria história das ideias e teorias pedagógicas algumas pistas que fundamentassem as suas hipóteses, a autora se deparou com pessoas e textos que, como ela, "estavam interessadas em questionar esse mesmo conceito genérico de metodologia do ensino, cujos trabalhos publicados, com as mais diversas abordagens, refletiam essa mesma preocupação".

Um dos autores que concorda com Manfredi (1996) é Masetto, ao diferenciar "estratégia' de "técnica", quando na verdade ele está se referindo à metodologia de ensino. Na percepção de Masetto (2003), as diferenças entre os termos "método" e "metodologia" estão ligadas às estratégias e à técnica que o professor utiliza em sua metodologia de ensino e relacionam instrumentos para o alcance de determinados objetivos. Para esse autor,

Estratégia é uma maneira de se decidir sobre um conjunto de disposições. Ou seja, são os meios que o docente utiliza para facilitar a aprendizagem dos estudantes, enquanto a técnica, além dos meios, inclui os recursos "materiais que estão relacionados aos instrumentos utilizados para atingir determinados objetivos (MASETTO, 2003, p. 88).

Ao ampliar o conceito de metodologia, cita a Declaração Mundial sobre Educação Superior no Século XXI (1998) e frisa que os docentes deveriam estar ocupados, sobretudo em ensinar "[...] a aprender e a tomar iniciativas, ao invés de serem unicamente fontes de conhecimento" (MASETTO, 2003, p. 16). Defende ser necessária a criação de programas de desenvolvimento para instituições de ensino superior e ressalta que não se trata de uma busca sobre erros de métodos que são aplicados atualmente, mas, ao contrário, é necessário avaliar as mudanças que provocam e modificam metodologicamente o ensino superior, pois o mesmo se refere à formação de profissionais inseridos no mercado nas próximas décadas. 
Nessa mesma direção, Kuenzer (2001) concorda com a importância das metodologias de ensino que, na educação superior sempre foi relegada, mas ganhou impulso nas discussões acadêmicas. Com a denominação de "metodologias ativas", elas têm se apresentado como uma estratégia para superar a chamada "educação conteudista", ou "tradicional" que, é mais relacionada à transmissão de conhecimento e à memorização. A autora, ainda, analisa que existe uma defasagem do ensino superior no que se refere a questões de conteúdo e, além disso, é evidente que o objetivo da educação superior não será atendido se permanecer atrelado a ferramentas antigas que não conseguem mais atender às demandas do ensino profissional e superior.

Cabe frisar que as metodologias ativas de ensino e aprendizagem têm sido alvo de discussões e, também, uma grande ênfase tem sido dada à sua provável supremacia nos resultados alcançados em relação às metodologias tradicionais, principalmente no ensino superior, como têm demonstrado algumas pesquisas já publicadas, como Berbel (2011). Conforme estudos realizados pela autora, é possível evidenciar a necessidade de inovar nas metodologias de ensino, ou seja, nas formas de ensinar e aprender como estratégia para resultados mais eficazes. Conforme o autor,

As Metodologias ativas baseiam-se em formas de desenvolver o processo de aprender, utilizando experiências reais ou simuladas, visando às condições de solucionar, com sucesso, desafios advindos das atividades essenciais da prática social, em diferentes contextos (BERBEL, 2011, p. 28).

Adotando o conceito de estratégia, o autor ressalta que as estratégias de ensino norteadas pelo método ativo apresentam as seguintes características principais: o aluno deve ocupar o centro do processo de ensino; deve haver a promoção da autonomia do aluno; a posição do professor deve ser de mediador, ativador e facilitador dos processos de ensino e de aprendizagem; deve haver estímulo à problematização da realidade, à constante reflexão e ao trabalho em equipe.

Na percepção de Berbel (2011), essas características se interrelacionam e são indissociáveis numa sala de aula pautada pelo método ativo. A aprendizagem ativa ocorre 
quando o aluno interage com o assunto em estudo - ouvindo, falando, perguntando, discutindo, fazendo e ensinando, sendo estimulado a construir o conhecimento, ao invés de recebê-lo de forma passiva. Nesse sentido, trata-se de um novo ambiente de aprendizagem, em que professor e alunos passam a atuar de forma interativa, com apoio das tecnologias, mas o professor é o orientador, o mediador do processo de aprendizagem, e não apenas a fonte única de informação e conhecimento. Conforme Almeida (2005-2006, p. 4)

[...] as potencialidades já ressaltadas da tecnologia digital não são suficientes para garantir a aprendizagem, tampouco indicam que uma única tecnologia seja adequada a todas as situações educacionais. Os propósitos da atividade, as necessidades contextuais, os temas dos estudos e as estratégias a desenvolver são os indicadores de quais tecnologias devem ser integradas ou se é apropriado utilizar tecnologias em determinada situação educacional.

Isso equivale a dizer que há, dessa forma, a necessidade de envolver o aluno como protagonista de sua aprendizagem e, implica desenvolver ainda o senso crítico diante do que é aprendido, bem como desenvolver competências para relacionar esses conhecimentos ao mundo real.

Conforme apresentado, a metodologia ativa é mais centrada na aprendizagem; a atividade é fundamento da concepção pedagógica da Escola Nova, a qual criou um divisor em relação às metodologias tradicionais de ensino (MANFREDI, 1996). O escolanovismo defendeu que as metodologias de ensino precisavam ser reconfiguradas e o professor deixaria de ser o centro do processo educativo, lugar agora do aluno que passaria a agir ativamente nas aulas baseadas em seus interesses. É unânime entre os autores visitados que o conceito de metodologia ativa que ressurge nos últimos anos não retira o papel de protagonista do aluno. O que muda é a função do professor que passa a ser a de "mediador", superando a ideia de "transmissor". A crítica se refere à passividade do aluno diante do protagonismo do professor em relação ao ensino, cujas bases vieram do entrelaçamento com as dimensões pedagógicas, metodológicas e didáticas, políticas e éticas.

Para que o aluno tenha um papel ativo é necessário saber lidar com diferenças em 
sala de aula, reconhecer os desafios a serem enfrentados, a fim de conviver com as mudanças permanentes não apenas na instituição de ensino, mas, também, na sociedade e no mundo produtivo, considerando as finalidades da educação no nível superior. Cabe, ainda, entender a lógica da tecnologia aplicada ao mercado como fonte criadora e desenvolvedora de novos processos e novas demandas mercadológicas. $\mathrm{O}$ uso de metodologias ativas pode favorecer a adequação da educação às novas exigências de uma sociedade globalizada e tecnológica, pois, no exterior da universidade, a cobrança para com o cidadão está diretamente ligada às suas competências, também desenvolvidas em sala de aula. Desse modo, passa-se a questionar, até mesmo, os processos tradicionais de avaliação que, em não raros casos, visam padronizar os saberes que impactam no desenvolvimento do aluno.

Nesse contexto, Moran (2007. p. 33) enfatiza que, se a intenção é que os alunos sejam proativos precisa-se "adotar metodologias em que os alunos se envolvam em atividades cada vez mais complexas, em que tenham que tomar decisões e avaliar os resultados, com apoio de materiais relevantes". E, ainda, frisa que se a intenção é "que sejam criativos, eles precisam experimentar inúmeras novas possibilidades de mostrar sua iniciativa". Desta forma, para desenvolver competências e abordar temas mais complexos em sala de aula, fazendo com que o aluno tome decisões, é preciso adotar metodologias que atendam a esta necessidade e permitam aos alunos apresentar seu potencial e desenvolvê-lo.

\section{Metodologias Ativas em um Curso de Administração}

Torna-se fundamental repensar as práticas pedagógicas e as metodologias até então utilizadas, uma vez que o uso de metodologias ativas pelos docentes está atrelado à aprendizagem ativa. Dessa forma, é resultado de um processo avançado de ação e reflexão, inclusive das próprias instituições de ensino superior, que estão expostas a um grande desafio no que se refere ao compromisso com uma formação que possibilite suprir as demandas da sociedade. 
O instrumento de coleta de dados foi aplicado na forma de questionário misto, no mês de novembro do ano 2017, em sala de aula aos 25 alunos que aceitaram participar da pesquisa, após a aprovação do projeto de pesquisa pelo Comitê de Ética. O questionário compôs-se de 10 (dez) questões fechadas e foi divido em duas partes. A primeira parte referese aos dados visando delinear o perfil dos participantes da pesquisa e a segunda parte referese às informações relativas às seguintes dimensões da formação: aptidão para administrar uma empresa; aplicabilidade dos conteúdos do curso de administração; eficácia do ensino e da metodologia utilizada; domínio de conteúdo técnico da área de administração; dificuldades enfrentadas na utilização de ferramentas específicas da administração na função pretendida; preparação para o mercado de trabalho e reconhecimento da importância das metodologias ativas na aprendizagem.

Os dados coletados permitiram delinear o seguinte perfil dos participantes da pesquisa: $36 \%$ são sexo feminino e $64 \%$ são do sexo masculino. Quanto à idade, $40 \%$ têm até 25 anos de idade; $56 \%$ têm entre 25 e 35 anos e $4 \%$ entre 35 e 45 anos. No que se refere à experiência profissional, $16 \%$ trabalham há mais de 10 anos, $8 \%$ possuem um ano ou menos de experiência; $24 \%$ têm entre um ano e três anos de experiência; $32 \%$ trabalham há mais de 3 (três) e até 5 (cinco) anos. Relativamente à função, 32\% exercem a cargo de analista, 24\% atuam em cargo de liderança, $20 \%$ ocupam cargo de gerência, $8 \%$ possuem cargos de direção e $16 \%$ inserem-se na categoria outros.

Após a sistematização das informações e dados coletados, verificou-se que $16 \%$ dos alunos respondentes se sentem aptos a enfrentar o mercado de trabalho na função de administração de empresa; $64 \%$ responderam que se sentem parcialmente seguros e $20 \%$ se sentem indiferentes à consciência de aptidão para administrar uma empresa. Com relação à aplicabilidade dos conteúdos estudados no dia a dia nas organizações, verifica-se que $4 \%$ dos alunos discordam totalmente; $8 \%$ discordam parcialmente; $28 \%$ são indiferentes e $60 \%$ concordam parcialmente. Esse indicador pode sofrer uma influência da profissão que o aluno já exerce enquanto realiza o curso superior e, em casos específicos, não consegue adaptar 
certas ferramentas e/ou conteúdos em suas rotinas, visto as especialidades de cada profissão.

Com relação ao conhecimento técnico como fator determinante no mercado de trabalho, na percepção dos alunos é que esse conhecimento é um fator importante para a inserção no mercado de trabalho, $16 \%$ dos alunos discordam totalmente que é a falta de conhecimento que dificulta a empregabilidade e $8 \%$ discordam parcialmente. 0 que chamou a atenção foi o percentual de $40 \%$ se mostraram indiferentes sobre essa questão e $36 \%$ concordam parcialmente. Sobre as dificuldades em utilizar as ferramentas específicas de administração na função profissional, os resultados obtidos mostram que $76 \%$ discordam totalmente e $8 \%$ parcialmente; $8 \%$ dos alunos se manifestaram indiferentes à questão e $8 \%$ concordaram que encontraram dificuldades para uso dessas ferramentas. Com relação ao papel das universidades e do Curso de Administração na preparação para o mercado de trabalho, os alunos foram questionados se atendeu de forma adequada e $8 \%$ afirmaram que não prepara totalmente; $24 \%$ disseram que prepara parcialmente e $68 \%$ se mostraram indiferentes em relação à essa questão.

Relativamente à importância das metodologias ativas no processo de ensino e formação para a função de administrador, foi observado que $80 \%$ dos participantes da pesquisa concordam totalmente que as metodologias ativas contribuem significativamente para a formação do administrador e $20 \%$ concordam parcialmente. Os indicadores obtidos nesta dimensão retratam que os alunos, ao aderirem às metodologias ativas, também reconhecem a sua importância no processo de ensino e na eficácia da aprendizagem. Por estarem no último da graduação, esse resultado tem sua relevância, pois os alunos puderam realizar uma comparação das metodologias ativas com os demais métodos por eles vivenciados ao longo do curso.

Esses dados confirmam o caráter positivo do uso de metodologias ativas no processo pedagógico do ensino superior, indo ao encontro do que foi apresentado por Berbel (2011). A autora frisa que o engajamento do aluno na dinâmica pedagógica é muito importante e que o uso dessas metodologias nas aulas favorece a compreensão dos conceitos estudados por 
parte do aluno. Foi utilizada uma planilha no modelo likert, contendo 10 (dez) questões referentes ao ensino, às metodologias, ao envolvimento dos alunos e aprendizado dos conteúdos da disciplina.

Esses resultados mostram que o ensino e a aprendizagem no nível superior de ensino são fortemente impactados pelas mudanças advindas das reconfigurações do mercado, da evolução das tecnologias e das novas demandas dos próprios estudantes. Evidenciou, também, que os estudantes chegam ao ambiente universitário munidos de expectativas e necessidades profissionais, buscando se preparar profissionalmente para conquistar um lugar ou uma posição no mercado de trabalho, projetando na figura do professor a realização de seu sonho profissional.

Esses resultados encontram respaldo em Masetto (2010; 2012), que afirma ter as metodologias função fundamental, quando utilizadas pelos professores em sala de aula de forma a reconhecer as necessidades dos alunos e valorizar os seus conhecimentos prévios e, principalmente, provocar um ambiente de aprendizagem constante e significativa. Entendese que as metodologias ativas devem ser valorizadas para que se desenvolva a liberdade, autonomia e as tomadas de decisões no processo pedagógico. Nesse sentido, cabe ressaltar que, principalmente quando se trata da preparação para a atuação profissional, como é o caso do Curso de Administração, isso é fundamental. Entretanto, seguindo as orientações de Berbel (2011), é o professor que deverá ter o controle do método, a liderança da atividade, garantindo uma postura pedagógica com intencionalidades bem definidas, o que evidencia, conforme Pimenta e Anastasiou (2010), o caráter social entre o ensinar e o aprender, que se efetiva por meio das práticas entre o sujeito professor e o sujeito aluno.

Diante do exposto, considera-se, com base em Cunha (2006), que ensinar é uma função complexa e se torna rica quando a troca entre professores e alunos ocorre em interface com os conteúdos desenvolvidos, tornando a relação ensinar e aprender mais significativa. A complexidade que envolve a relação professor e aluno foi identificada com a análise dos resultados da pesquisa que deu origem a este artigo. Foram identificados, no estudo, alguns 
fatores essenciais ao professor, que são condição sine qua non para o sucesso de uma aula com a utilização da mediação da aprendizagem com metodologias ativas no ensino superior, alguns dos quais são tratados neste artigo, a saber: mudanças no perfil do aluno do curso superior; domínio do conteúdo; experiência profissional do professor; superação de paradigmas tradicionais da educação superior, conforme apresentado em sequência.

\section{Fatores que Influenciam no uso de Metodologias Ativas}

De início, cabe considerar dois pontos importantes: primeiro, que a partir da década de 1990, diversas mudanças vêm ocorrendo na educação superior, principalmente, com a publicação da Lei de Diretrizes e Bases da Educação Nacional (LDB), no 9394, de 1996. Em segundo lugar merece destaque a instituição do Sistema Nacional de Avaliação do Ensino Superior (SINAES), pela Lei no 10.861, de 2004. Desde então, diante das demandas do mercado e da própria exigência do MEC por mais qualidade do ensino, via avaliação institucional, os alunos universitários vêm sendo convocados a participar ativamente desse movimento pela melhoria da qualidade de ensino, por meio do SINAES.

\section{Perfil do aluno do curso superior}

Os alunos do ambiente universitário estão cada vez mais críticos sobre as disciplinas com relação aos conteúdos aplicados em sala de aula e, principalmente, sobre a sua aplicabilidade no ambiente de trabalho. Nesse novo cenário, o aluno do ensino superior surge como um agente importante no processo de transformação da sala de aula, uma vez que a eles, no mercado de trabalho, vem sendo exigido assumir uma postura dinâmica e ativa de forma a produzir respostas rápidas para um mundo em mudanças aceleradas e contínuas, denominado processo de reestruturação produtiva do capitalismo global, como descrito por Dourado (2008). 
Os autores se referem às bases formuladas para uma economia assentada na acumulação flexível (HARVEY, 1992) e, de outro, à constituição de uma sociedade técnicocientífica-informacional ou sociedade do conhecimento (LOJKINE, 1995), centrada na produção de novas tecnologias e na rearticulação e criação de processos organizacionais inovadores. Masetto (2012) defende que as instituições do ensino superior devem estar atentas às novas demandas e às necessidades do aluno nesse ambiente de mudanças constantes, pois neste contexto o ambiente educacional com suas práticas de ensino se torna fundamental para que proporcione aos alunos competências cognitivas e instrumentais necessárias à sua formação profissional.

Considerar as finalidades do ensino superior, asseguradas pela LDB, № 9394/1996, o desenvolvimento de uma pessoa crítica, com a capacidade de pensar e intervir nas mudanças, implica em ser capaz de utilizar da sua formação cultural e científica para atuar de forma dinâmica e participativa, provocando e sendo provocado pelas novas demandas, tanto profissionais quanto sociais, econômicas e culturais e, para que isso ocorra, se fazem necessárias adequações nas metodologias de ensino e na própria organização dos conteúdos.

\section{Domínio do conteúdo}

Pimenta e Anastasiou (2010) destacam que os professores universitários devem conhecer os conceitos da aprendizagem e ter como base as suas metodologias para alcançar seus objetivos em sala de aula. Sem a didática, o professor corre o risco de praticar a ensinagem, e isso não contribui para que os alunos aprendam o que ele pretende ensinar. Com relação ao conceito de "ensinagem", Pimenta e Anastasiou (2010) afirmam:

Apreender não é um processo que se efetive sem rotinas ou ocorra de forma espontânea ou mágica. Ao contrário, exige, exatamente, em virtude da intencionalidade contida no conceito de ensinagem, a escolha e execução de uma metodologia adequada aos objetivos e conteúdos do objeto de ensino aos alunos. Exige do professor, além do domínio do conteúdo a ser ensinado, a competência para uma docência da melhor qualidade (PIMENTA; ANASTASIOU, 2010, p. 211). 
No caso do Curso de Administração, o professor tem convivido com alunos em sala de aula que buscam a formação de competências para serem aplicadas na Administração das organizações, mas também em todas as áreas adjacentes que envolvem o ato de administrar. Nesse sentido, a sala de aula se torna um espaço de gerenciamento de aprendizagens em que se reúnem diversos alunos e professor, os quais darão aplicabilidades diferentes aos conceitos. Mas, o que não difere são as competências básicas para o desenvolvimento acadêmico e profissional que estão descritas nos objetivos do ensino superior.

De acordo com Almeida (2011, p. 23), o desenvolvimento de competências no ensino superior tem a função de:

a) propiciar o domínio de conhecimentos, métodos e técnicas científicos, assegurando o domínio científico e profissional do campo específico, e que sejam ensinados criticamente (isto é, em seus nexos com produção social e história da sociedade);

b) considerar a interdisciplinaridade como possibilidade de superação de uma visão e formação fragmentadas;

c) desenvolver capacidade de reflexão que conduza à autonomia do aluno na busca de conhecimentos;

d) considerar o ensino como atividade integrada à de investigar;

e) desenvolver habilidades de pesquisa que se integrem aos cursos e aos processos formativos, superando uma iniciação científica que, por vezes, isola o estudante do curso e se fixa dos laboratórios dos professores;

f) substituir o ensino limitado à transmissão de conteúdo, por um ensino que se constitua em processo de investigação, análise, compreensão e interpretação dos conhecimentos e de seus fundamentos e métodos em seus aspectos epistemológicos, históricos, sociais, culturais, éticos e políticos; g) valorizar a avaliação diagnóstica e compreensiva da atividade pedagógica mais do que a avaliação como controle;

A figura do professor é imprescindível, não somente por saber mediar este processo de formação no ensino superior, mas como aplicá-lo de maneira efetiva (MASETTO, 2003). Nesse sentido, professor desse nível de ensino deve buscar não somente relacionar os conteúdos com a profissão escolhida, mas abrir portas para o desenvolvimento e análise crítica do processo que ocorre, de forma que o aluno possa tomar decisões de maneira sustentada pelos seus conhecimentos, tanto em sala de aula como na sociedade. De modo 
geral, uma disciplina vale pelo conteúdo que aborda, aprofunda e discute.

Considerando as especificidades da educação superior, autores como Franco (2016) ressaltam a necessidade de refletir a estruturação do ensino superior e a formação de professores para atuar neste nível de ensino. As especificidades dos saberes pedagógicos não eram componentes necessários à formação de professores universitários e, por isso, nunca foi exigido a formação pedagógica necessária para o exercício profissional da docência no nível superior. A seleção de docentes, tradicionalmente, privilegiou os conhecimentos profissionais como únicos requisitos para a docência, mas essa realidade não atende mais ao cenário atual em que as tecnologias estão na ordem do dia, e assim, conhecer a aplicabilidade dos conteúdos não basta. As competências profissionais do professor no ensino superior vão além do conhecimento e da experiência de mercado.

Diferentemente dos outros graus de ensino, "esse professor se constituiu, historicamente, tendo como base a profissão paralela que exerce ou exercia no mundo do trabalho" (CUNHA, 2010, p. 526) e, por isso, a ideia de que "quem sabe fazer sabe ensinar" deu sustentação à lógica do recrutamento de docentes. Isso não exclui a exigência do domínio do conteúdo por parte do professor que ministra qualquer disciplina. De acordo com Borges e Oliveira (2020), a integração das tecnologias no ensino superior de forma produtiva implica em o docente considerar os três conhecimentos, pedagógico, de conteúdo e tecnológico, pois para ensinar com tecnologias é preciso aprender com tecnologias, isto com base em Mishra e Koehler (2006).

Assim sendo, Borges e Oliveira (2020) mencionam que não há "uma única solução tecnológica para cada curso, professor ou ensino" e, assim, no processo de ensino e aprendizagem é necessário, portanto, haver integração desses três conhecimentos por parte do docente, o qual pode atuar com base em estratégias adequadas ao cenário em que atua. Dessa forma, esses autores retomam Mishra e Koehler (2006) para afirmar que o conhecimento tecnológico, de conteúdo e pedagógico, devem estar sempre em um sistema complexo, em uma tríade indissociável. 


\section{Experiência profissional do professor}

A docência no ensino superior como uma atividade complexa já pode ser considerada consenso entre os pesquisadores que, de alguma forma, investigam e discutem o tema, dentre eles Cunha (2010) e Masetto $(2003,2012)$. Eles reconhecem que os saberes para a docência no ensino superior exigem uma preparação acadêmica e profissional, numa perspectiva teórica e prática, mas também experiência profissional no sentido de poder articular os conteúdos à realidade das exigências do mundo corporativo. A construção dos saberes experenciais se dá ao longo do exercício da profissão, bem como o comprometimento profissional e com formação continuada assumida no exercício da profissão. Os saberes da experiência são mobilizados pelos docentes, tornando a formação mais eficaz, considerando boa formação aquela que contemple as reais necessidades de formação dos seus discentes.

Nesse contexto, a pedagogia aparece como contribuinte dos docentes, cabendo ao professor a responsabilidade por um ambiente de aprendizagem ativa, ou seja, em que necessariamente ocorra o envolvimento ativo do aluno em seu processo de formação (PIMENTA; ANASTASIOU, 2010). A implementação das metodologias ativas como mediação pedagógica equivale a estratégias que podem favorecer uma motivação autônoma e o fortalecimento da percepção do aluno de ser ele a origem da própria ação no processo de aprendizagem, como defendido por Berbel (2011).

Analisando as finalidades da educação superior no mundo contemporâneo, Pimenta e Anastasiou (2010, p. 165) identificam três aspectos que impulsionam o desenvolvimento profissional do professor universitário.

São eles: a transformação da sociedade, se seus valores e de suas formas de organização e trabalho; o avanço exponencial da ciência nas últimas décadas; a consolidação progressiva de uma Ciência da Educação, possibilitando a todos o acesso aos saberes elaborados no campo da Pedagogia.

A contribuição de Franco (2016) faz-se pertinente ao relacionar a condição do professor iniciante em sua carreira no ensino superior. A autora concorda com Pimenta e Anastasiou (2010) quando reconhece que o professor se depara com diversos níveis de alunos 
em sala de aula. Cada qual com sua característica e todas devem ser observadas e trabalhadas, e isso faz com que o professor universitário tenha que buscar conhecimentos pedagógicos, que possam colaborar para que consiga lidar com essa diversidade e propor metodologias que consigam a integração e sinergia entre conteúdo e métodos em sala de aula, tendo em vista alcançar objetivos pré-estabelecidos.

Sem o mínimo de experiência, além do domínio do conteúdo a ser ensinado, a competência para uma docência poderá levar à perda em qualidade de ensino e de aprendizagem. A prática representa um fator contribuinte na competência docente, mas não garante por si mesma o desenvolvimento em sala de aula de um ambiente participativo e de atividades dinâmicas para o aluno com utilização de metodologias variadas e das tecnologias digitais. Para Mishra e Koehler (2006), refletir acerca do que os docentes precisam saber em relação aos modos que essas tecnologias podem ser integradas aos processos educativos no nível superior de ensino, pode contribuir para a real integração dessas tecnologias na educação. Esses autores defendem que a formação dos docentes integra o processo de ensino e aprendizagem, sendo complexa e baseada em vários tipos de conhecimento.

No ensino superior, ações direcionadas para a formação continuada dos professores e a reflexão sobre a própria prática integram o processo de atuação e a construção dos conhecimentos dos docentes. Evidenciam-se, portanto, as discussões contínuas acerca do trabalho docente no ambiente educacional, sendo muitas as indagações que abordam a identidade profissional e a formação do professor ao longo da vida. O professor passa a ser fundamental ao desenvolver técnicas pedagógicas que atendam as condições e necessidades dos alunos, por meio de métodos em que há compartilhamento na construção do conhecimento, o que pode propiciar que a aprendizagem se desenvolva de significativamente. Tudo com o entendimento de que a "sensibilidade ante o aluno; valorização dos saberes da experiência; ênfase nas relações interpessoais; aprendizagem compartilhada; integração teoria/prática e, também o ensinar a partir do respeito à aprendizagem do aluno" são fatores essenciais na formação para a vida (ISAIA et al., 2006, p. 13). 
A formação superior passa por um processo de reconhecimento da importância do conceito pedagógico e a sensibilização para docência, em que não somente a competência prática é valorizada (MASETTO, 2012), como também o desenvolvimento de propostas para o aprender por meio da prática sustentada pelo conhecimento pedagógico do professor. $\mathrm{Na}$ percepção desse autor, esses fatores, trabalhados em conjunto, criam ambientes universitários dinâmicos e significativos para os alunos, desenvolvendo habilidades para lidar com as demandas externas e a necessidade de se adaptar aos cenários diversos do mercado.

[...] as próprias instituições [...] com seus docentes da área de educação, devem criar um programa ou serviço permanente de formação pedagógica para seus professores. [...] para uns poderá ser uma troca de experiências; para outros, uma atividade de sensibilização para a docência. Ainda, pode ser considerada uma oficina de planejamento ou uma forma de experimentar algumas técnicas de aula, e assim por diante. $O$ importante é que seja uma atividade que interesse ao grupo e seja prazerosa (MASETTO, 2012, p. 202).

Dessa forma, um ambiente desenvolvendo estratégias de aprendizagem permanente é importante para o professor. Ele passa a ser um profissional que conhece a si mesmo e sabe de suas competências para superar cada momento em sala de aula.

Pode-se dizer que ele consegue enfrentar as realidades educacionais, utilizando estratégias de acordo com as características dos alunos e as disponibilidades tecnológicas; trabalha com pessoas de diferentes formações e consegue mesmo assim fazer com que eles atuem em equipe em sala de aula, construindo um ambiente colaborativo de aprendizagem, em que todos podem aprender não somente para sua função profissional, mas como cidadão atuante na sociedade.

\section{Superação de paradigmas tradicionais da educação superior}

As metodologias ativas têm sido amplamente discutidas no cenário da educação superior como proposta de aproximar os conteúdos curriculares à realidade dos alunos, 
reorganizar suas propostas de ensino e promover novas formas de aprendizagem. Para Masetto (2003), o professor exerce uma função importante no desenvolvimento do aluno, pois quando desenvolve uma parceria com os estudantes, eles passam a fazer, juntos, o que antes era feito somente por uma das partes. Para o autor, em dias atuais, o maior desafio para o docente do ensino superior é desenvolver práticas que levem os alunos a participarem efetivamente da aula. Também enfatiza que a prática pedagógica no ensino superior requer mudanças e, principalmente, a quebra de paradigmas relacionados à autonomia do aluno e à mediação do professor.

Pode-se compreender que Masetto (2003) se refere à crença tradicional que ainda está presente nas instituições e nos discursos pedagógicos, qual seja, que o professor ensina ao aluno que nada sabe. O professor, sendo o ensino presencial ou à distância, se utiliza de instrumentos como materiais escritos e audiovisuais em suas aulas e a grande dificuldade está em quebrar esse ciclo repetitivo em sala de aula. No entanto, tradicionalmente, a metodologia despreza algo fundamental, que é a pretensão e a expectativa do aluno ao procurar um curso superior. Com isso, é muito comum o professor não conseguir atingir o resultado esperado devido à falta de identificação por parte do aluno com o conteúdo e, principalmente, com aquilo que ele busca nas aulas.

Diante do exposto, as metodologias ativas passam a ser um passo importante nesse processo de transformação do ensino superior, pois trazem com ela novas práticas que dão suporte as diretrizes curriculares nacionais dos cursos de graduação. O conceito de metodologias ativas, apesar de não ser único, traz uma ideia comum de interação e participação efetiva do aluno nas atividades educativas e mais autonomia no seu próprio processo de aprendizagem e formação, que é contrária à premissa predominante no ensino tradicional. O método ativo passa a desenvolver o processo aprendizagem por meio de experiências e simulações que buscam apresentar soluções para os desafios que thes são apresentados, inclusive relacionados às situações de mercado que são colocados em sala de aula em forma de atividades e práticas em diferentes contextos. 
Percebe-se que existe uma relação entre metodologias ativas, dando suporte ao desenvolvimento de competências necessárias para a formação do indivíduo no ensino superior, incluindo o seu crescimento pessoal e profissional. Nesse foco, Barbosa e Moura (2013) afirmam que as metodologias ativas são uma forma estimulante de realizar atividades com os alunos em sala de aula, pois trazem com ela interatividade, a cooperatividade e a competitividade, que estimulam o aluno a interagir e a buscar as recompensas do aprendizado. As metodologias ativas permitem também abranger os novos perfis profissionais e promover a resolução de problemas individuais e coletivos, mediante um contexto situacional vivenciado, como analisado por Berbel (2011). Para a autora,

[...] as metodologias ativas impulsionam a aprendizagem, através da superação de desafios, da resolução de problemas e da construção do conhecimento. As metodologias ativas têm o potencial de despertar a curiosidade, à medida que os alunos se inserem na teorização e trazem elementos novos, ainda não considerados nas aulas ou na própria perspectiva do professor. Quando acatadas e analisadas as contribuições dos alunos, valorizando-as, são estimulados os sentimentos de engajamento, percepção de competência e de pertencimento, além da persistência nos estudos, entre outras (BERBEL, 2011, p. 28).

Pode-se inferir, portanto, que as metodologias ativas trazem com elas a abertura das possibilidades de inovação nas práticas pedagógicas e de mudanças na própria estrutura orgânica da sala de aula do ensino superior, ao promover mais atenção e participação dos alunos e, ao mesmo tempo em que os motiva a pensar, criticar e analisar toda a informação, desenvolve a autonomia e a capacidade de tomar decisões.

\section{Considerações Finais}

A experiência com metodologias ativas no ensino superior tem demonstrado que as dificuldades para sua implantação, de forma mais massiva entre os docentes, são inúmeras e atinge grande dos professores do ensino superior. Observa-se que as próprias instituições de 
ensino superior têm ainda um longo caminho a percorrer, embora diversas delas já contem com profissionais iniciando essa caminhada em direção à implantação de soluções inovadoras do ponto de vista pedagógico.

Ao longo deste estudo foi possível observar que o ensino baseado unicamente na transmissão de conteúdos pelo professor e na passividade do aluno, como ouvinte em sala de aula, precisa dar lugar a práticas de ensino inovadoras e que as metodologias ativas de ensino podem contribuir para isso. Elas vêm ganhando, cada vez mais, espaço no cenário educacional, sendo tratadas, muitas vezes, como inovação por trazerem contribuições positivas nos processos de ensino e de aprendizagem e por romper com a prática tradicional.

Ao falarem sobre a mudança na dinâmica das aulas e mais participação dos alunos, os estudantes que participaram da pesquisa referida neste artigo revelaram o aumento de interesse e da curiosidade pelos temas tratados, manifestados em uma espécie de desejo de que a aula não acabasse. Isto vai ao encontro do que Mazur (1996) coloca ao relatar uma experiência em sala de aula do ensino superior com a utilização de metodologias ativas, quando identificou que a percepção dos alunos é que tornam a aprendizagem mais ativa e os resultados mais eficazes com a presença dessas metodologias nas aulas.

Sem a intenção de generalizar uma metodologia ideal para a sala de aula do ensino superior e nem mesmo indicar percursos aos professores, o estudo apresentado sugere mudanças no formato das aulas no nível superior de ensino, até mesmo para estimular a permanência dos alunos nos cursos, diminuindo a evasão. Há que se frisar, todavia, que é possível pensar em ampla liberdade na escolha das atividades e metodologias de ensino empregadas nas aulas, de maneira a colocar o aluno no centro do processo educativo, no lugar de admitir esse processo baseado na pedagogia tradicional com ações muito limitadas em relação à participação dos alunos nas aulas.

Foi possível inferir que a docência no ensino superior, enquanto atividade profissional, está diretamente relacionada à performance da atividade pedagógica e não apenas ao conhecimento de uma área específica. O conceito de competência, nesse sentido, está 
atrelado a um conjunto de saberes e habilidades, estruturadas de modo a formar um conjunto ideal e qualificado para que o profissional exerça sua atividade com a expertise necessária. Nesse sentido, a competência deve ser entendida como uma combinação de conhecimentos, de saber fazer, de experiências e comportamentos que exerce, em um contexto preciso a chamada "expertise" que deve ser a marca constatada quando de sua utilização em qualquer situação profissional (MASETTO, 2010). Dessa forma, é preciso considerar que existem fatores que transcendem às instituições de ensino e vão ao encontro de demandas da sociedade moderna que fazem parte da complexidade que envolve a docência na educação superior.

A experiência pedagógica com metodologias ativas vem possibilitando ao professor pesquisador compreender como os alunos que vivenciam práticas interativas em sala de aula respondem e percebem as mudanças nas rotinas da sala de aula e, por isso, nenhuma metodologia deve ser desprezada. Porém, algumas metodologias utilizadas, já algum tempo (rotuladas de tradicionais) podem e devem ser adaptadas a uma nova realidade, com todos os subsídios integram a dinâmica de uma aula interativa. O método ativo ou a abordagem das metodologias ativas de aprendizagem se apresentam, portanto, não como um modelo de inovação, mas sim, de evolução no ensino. No entanto, o que o coloca em ascensão, é o fato de que fatores ambientais como a globalização e as novas tecnologias, afetam diretamente todos os níveis de ensino e, portanto, o aluno e sua postura profissional.

Ao utilizar metodologias ativas no processo de ensino, tanto o aluno como o professor, passam a ser atores de um processo dinâmico, em que ocorre a integração de conhecimentos e experiências que são fundamentais para um ensino, que possibilite gerar uma aprendizagem significativa e competências autônomas. Isso vai ao encontro das diretrizes curriculares do curso de Administração pesquisado, as quais já abordam a necessidade do desenvolvimento de competências que não podem ser somente conceituadas, mas, sim, desenvolvidas e praticadas.

Dessa forma, os alunos, ao aderirem às metodologias ativas, também reconhecem a sua importância na inovação das aulas e na eficácia do ensino e da aprendizagem. Em suma, 
as metodologias ativas representam ferramentas fundamentais para colaboração do processo de construção de conhecimentos, em que aluno e professor são protagonistas; sujeitos ativos que se interagem e trocam constantemente conhecimentos, fazendo do ambiente em que ocorrem as aulas um lugar facilitador da aprendizagem significativa.

\section{Referências}

ALMEIDA, M. I. de. Pedagogia universitária e projetos institucionais de formação e profissionalização de professores universitários. 2011. 147 f. Tese (Livre-Docência) Faculdade de Educação, Universidade de São Paulo, São Paulo, 2011. Disponível em: https://repositorio.usp.br/item/002253984 . Acesso em: 19 fev. 2019.

ALMEIDA, Maria Elizabeth Bianconcini de. Tecnologias na educação, formação de educadores e recursividade entre teoria e prática: trajetória do Programa de Pós-Graduação em Educação: currículo. Revista E-Curriculum, São Paulo, v.1, n.1, dez. - jul. 2005-2006. Disponível em: https://ken.pucsp.br/curriculum/article/viewFile/3165/2095 . Acesso em: 19 fev. 2019.

AUSUBEL, David Paul. Alguns aspectos psicológicos de la estructura del conocimiento. Buenos Aires: El Ateneo, 1973.

BARBOSA, Eduardo Fernandes; MOURA, Dácio Guimarães de. Metodologias ativas de aprendizagem na educação profissional e tecnológica. Boletim Técnico do Senac, v. 39, n. 2, p. 48-67, 2013. Disponível em: https://www.bts.senac.br/bts/article/view/349 . Acesso em: 19 fev. 2019.

BERBEL, Neusi Aparecida Navas. As metodologias ativas e a promoção da autonomia de estudantes. Ciências Sociais e Humanas, Londrina, v. 32, n. 1, p. 25-40, jan./jun. 2011. Disponível em: http://www.uel.br/revistas/uel/index.php/seminasoc/article/view/10326 . Acesso em: 19 fev. 2019.

BRASIL. Lei no 10.861/04, de 14 de abril de 2004. Institui o Sistema Nacional de Avaliação da Educação Superior - SINAES e dá outras providências. Brasília, 05 abr. 2004.

BRASIL. Ministério da Educação. Plano de Ações Articuladas. Brasília, DF: MEC, 2007.

BRASIL. Lei no 9.394, de 20 de dezembro de 1996. Estabelece as diretrizes e bases da educação nacional. Brasília, DF: Presidência da República, 1996. Disponível em http://www.planalto.gov.br/ccivil_03/LEIS/I9394.htm. Acesso em: 19 fev. 2019.

CUNHA, Maria Isabel da. Verbetes: formação inicial e formação continuada. Enciclopédia de pedagogia universitária. Brasília: MEC/INEP, 2006, p. 354. 
CUNHA, Maria Isabel da. O lugar da formação do professor universitário: o espaço da pósgraduação em educação em questão. Rev. Diálogo Educ., Curitiba, v. 9, n. 26, p. 81-90, jan./abr. 2009. Disponível em:

https://periodicos.pucpr.br/index.php/dialogoeducacional/article/view/3664/3580 Acesso em: 19 fev. 2019.

CUNHA, Maria Isabel; SOARES, Sandra Regina. Formação do professor: a docência universitária em busca de legitimidade. Salvador: EDUFBA, 2010.

CUNHA, Maria Isabel. Inovações na educação superior: impactos na prática pedagógica e nos saberes da docência. Em Aberto, Brasília, v. 29, n. 97, p. 87-101, 2016. Disponível em: http://rbep.inep.gov.br/ojs3/index.php/emaberto/article/view/3172 . Acesso em: 19 fev. 2019.

DOURADO, Luiz Fernandes. Políticas e gestão da educação superior: múltiplas regulações e reforma universitária no Brasil. In: VII Seminário Redestrado: nuevas regulaciones en américa latina, Buenos Aires, 2008. Anais [...]. Buenos Aires, 2008. Disponível em: http://flacso.redelivre.org.br/files/2013/03/1096.pdf . Acesso em: 19 fev. 2019.

FRANCO, Maria Amélia do Rosario Santoro. Prática pedagógica e docência: um olhar a partir da epistemologia do conceito. Revista Brasileira Estudos Pedagógicos [on-line], v. 97, n. 247, p. 534-551, set./dez. 2016. Disponível em: https://www.scielo.br/scielo.php?pid=S217666812016000300534\&script=sci_abstract\&tlng=pt . Acesso em: 19 fev. 2019.

HARVEY, D. Condição pós-moderna. Trad. Adail Ubirajara Sobral e Maria Stela Gonçalves. São Paulo: Loyla, 1992.

ISAIA, Sandra Maria et al. Revendo o Glossário RIES de Pedagogia Universitária: um diálogo interdiscursivo. In: VI ANPEd Sul, Universidade Federal de Santa Maria, Santa Maria, 2006. Anais [...]. Disponível em: https://www.ufsm.br/unidades-universitarias/ce/wpcontent/uploads/sites/373/2019/02/575677f0ed9819b7d787fdcb8e2702d0-1.pdf . Acesso em: 19 fev. 2019.

KUENZER, Acacia Zeneida. O que muda no cotidiano da sala de aula universitária com mudança no mundo do trabalho? In: CASTANHO, S.; CASTANHO, M. E. (org.). Temas e textos em metodologia do ensino superior. Campinas: Papirus, 2001.

LOJKINE, Jean. A revolução informacional. São Paulo: Cortez, 1995.

MANFREDI, Silvia Maria. Formação sindical no Brasil: história de uma prática cultural. São Paulo: Escrituras Editora, 1996.

MASETTO, Marcos Tarciso. Competência pedagógica do professor universitário. São Paulo: Summus, 2003.

MASETTO, Marcos Tarciso. O professor na hora da verdade: a prática docente no ensino 
superior. São Paulo: Avercamp, 2010.

MASETTO, Marcos Tarciso. Competência pedagógica do professor universitário. 2 ed. rev. São Paulo: Summus, 2012.

MAZUR, Eric. Peer Instruction: a revolução da aprendizagem ativa. Tradução: Anatólio Laschuk. Porto Alegre: Penso, 2015.

MAZUR, Eric. Peer Instruction: a user's manual. Boston: Addison-Wesley, 1996.

MISHRA, P.; KOEHLER, M. J. Technological pedagogical content knowledge: a framework for teacher knowledge. Teachers College Record, New York, v. 108, n. 6, p. 1017-1054, jun. 2006. Disponível em: http:// one2oneheights.pbworks.com/f/MISHRA_PUNYA.pdf. Acesso em: 25 fev. 2019.

MORAN, José Manuel. A educação que desejamos novos desafios e como chegar lá. Campinas: Papirus, 2007.

MORAN, José Manuel. Mudando a educação com metodologias ativas. Coleção Mídias Contemporâneas. SOUZA, C. A.; MORALES, O. E. T (org.). Convergência Midiáticas, Educação e Cidadania: aproximações jovens. v. II, p. 15-33, 2015. PG: Foca Foto-PROEX/UEPG.

Disponível em: http://www2.eca.usp.br/moran/wpcontent/uploads/2013/12/mudando_moran.pdf . Acesso em: 19 fev. 2019.

OLIVEIRA, André Luiz Martins de; BORGES, Rosimeire Aparecida Soares. Tecnologias digitais no ensino superior: inovação com a TPACK.1 ed. Curitiba: Appris, 2020.145 p.

PIMENTA, Selma Garrido; ANASTASIOU, Lea das Graças Camargos. Docência no ensino superior. 4. ed. São Paulo: Cortez, 2010. 